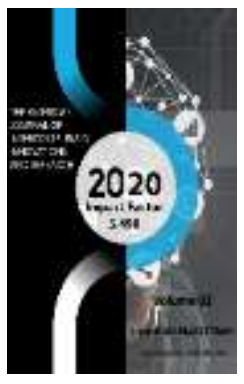

Journal Website: http://usajournalshub.c om/index,php/tajiir

Copyright: Original content from this work may be used under the terms of the creative commons attributes 4.0 licence.

\section{Efficiency Of Use Of Schemes Of Regulation Of Land Use Processes In Uzbekistan}

\author{
Altiev Abdurashid \\ Tashkent Institute Of Irrigation And Agricultural Mechanization Engineers, Doctor Of Science \\ In Economics., Docent., Department Of "Land Recourse Management" Q. Niyoziy Street \\ Tashkent City, Uzbekistan \\ Khalilova Barno \\ Tashkent Institute Of Irrigation And Agricultural Mechanization Engineers, Phd Student \\ Department Of “Land Recourse Management" Q. Niyoziy Street Tashkent City. Uzbekistan \\ Avilova Nilufar \\ Karshi Branch Of Tashkent Institute Of Irrigation And Agricultural Mechanization Engineers, \\ Assistant Teacher Department Of "General Sciences", Khanabad Shakh Street Karshi City. \\ Uzbekistan
}

\title{
ABSTRACT
}

The article presents the scientific and methodological basis of land use in the Republic of Uzbekistan. In particular, the differences and similarities between the definitions of "land use" by several scholars have been studied. The purpose and specific tasks of the land fund categories are described. The landuse system was critically analyzed and the inefficiency of land use categories of the Tashkent region, which is the object of research, was identified. Its causes have been investigated. In order to prevent these processes, the methodology of analysis and forecasting of these processes on the basis of cartographic and mathematical-cartographic methods was also analyzed. Suggestions are made for the development of land use forecasts based on some elements of the formation of land use schemes. In order to increase the efficiency of land use, it is necessary to clearly define the process of land use. A land-use scheme has been proposed to prevent identified deficiencies.

\section{KEYWORDS}

Land use, land fund, land use system, land use scheme, land use forecasts, land status, cartographic method, mathematical-cartographic method.

\section{INTRODUCTION}

Today, land use a socio-economic reality and the use of land resources as a socially important process demands researches. The essence of land use, structural organization and management are not fully studied. It is necessary to clarify this concept. Land use categories need further theoretical study of their types. Russian scientist S.Tkachuk gave the best definition for the concept of land use according to his definition he established "land 
use is the sum of production methods and social-economic forms of land resource use which is developing of the reasonable use of economic laws with harmony in nature laws" [2].

Uzbek scientists A.Chertovitsky, A.K.Bazarov,the concept of "land use" and the concept of "land management" was explained clearly, that is very common among specialist and has a broad or equal content and importance land management is a system of state measures for territory organization, which is one of the functions of the territorial aspect of land use and land use management. Each of a clear boundary between the concepts of "land use" and "land management" leads to confusion in the function of land use management and several miss understandings in their implementation and use. A science-based approach to the nature, content and function of land use is needed. The land-use system is "a combination of continuous, cyclical, multipurpose use of land resources by a developing society based on the conscious use of society and nature laws and market methods of managing this process"[5].

A.S.Altiev in his book "Economics of land use" discussed above-mentioned definitions. "There are some contradictory explanations of these definitions of the land-use system. He does not cover all the aspects of modern land use, i.e. The land-use system is influenced by certain relationships, style and methods require appropriate relationships that is why it is necessary to explain this definition through certain relations"[10].

Besides, in our opinion, if land use is carried out through the use of geoinformation technologies, generalizing the scientific and practical conclusions, there will be an increase in the efficiency of its use global environmental problems, such as climate change, desertification, biodiversity loss, air pollution and pollution of water resources and anthropogenic accidents related to industrial production are damaging the land and the environment as a whole. Because inefficient use of land, there are many cases of illegal occupation of land and the use of land plots by people for not reasonable purposes. From this point of vivo, it is important to study land fund categories and their condition. The land fund of the Republic of Uzbekistan has its characteristics according to the purpose and procedure of land use, which is divide into 8 categories according to Article 8 of the land code of the Republic of Uzbekistan [1].

Each land fund category performs a different function depending on their using purpose. Figure 1 below shows the land fund categories. 


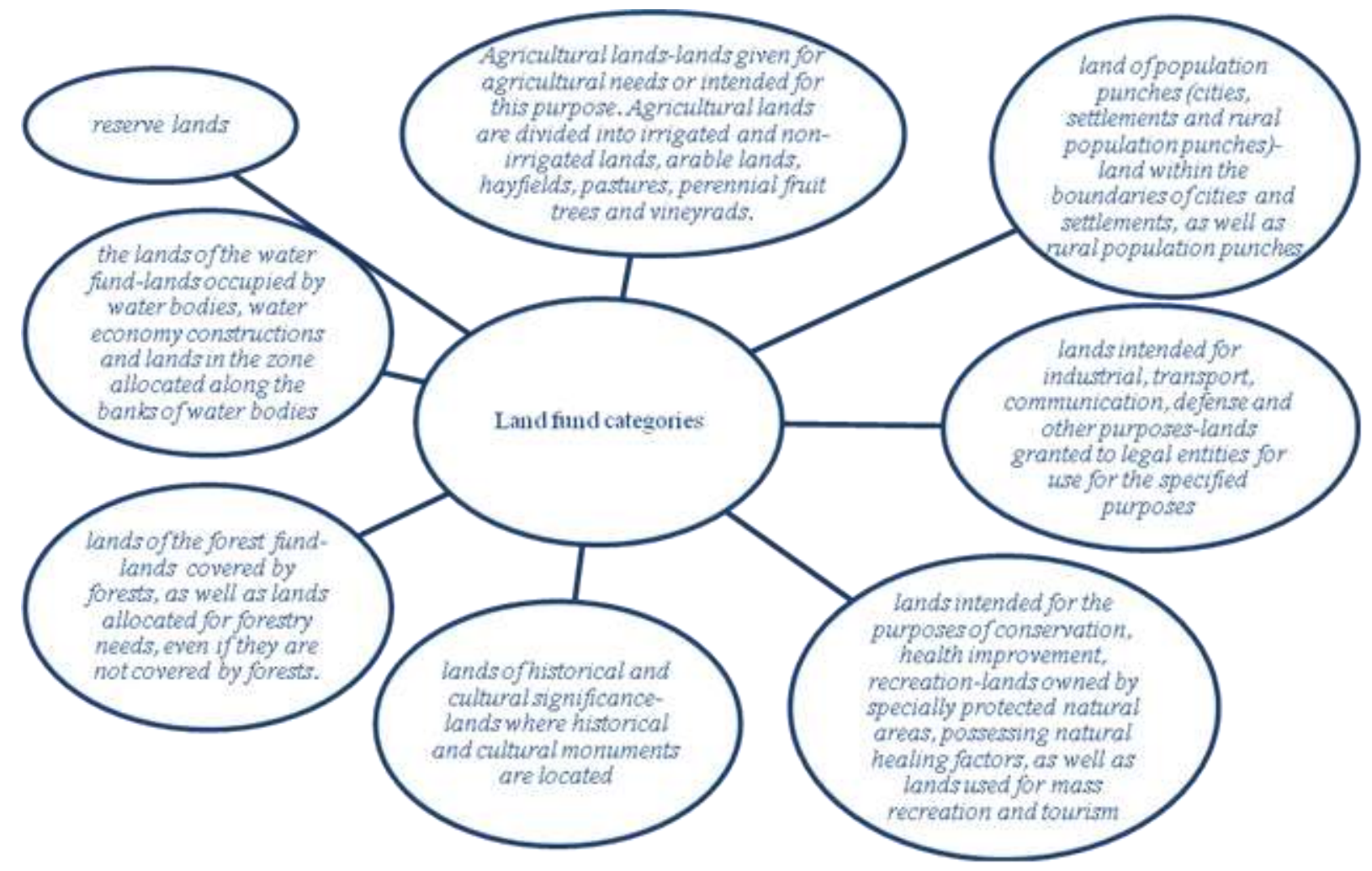

Figure 1. Land fund categories.

The above-mentioned land fund categories are further subdivided into land types. One of the important concepts of the land fund island type composition. It determines the rationality and efficiency of land use as a result of the multipurpose nature of the land resource use by society. The analysis of the above mentioned scientific land work shows that there is no systematic land use in the use of land fund categories. This situation does not allow the rational and efficient use of exited land fund categories.

"A system is a neat set of elements that interact with each other and has a certain connection and form a certain integrity, unity" [5].
Without a systematic approach to land use, the chances of passing them on to future generations as a resource will decline. In order to establish systematic land use, there is a need to research the formation of science-based and technical documentation applied to the production of land use schemes. In the land use scheme, land should be considered as not only a basic means of production but also as an object of market relations and socio-economic relation is society, as well as the basic units of the natural complex. The main purpose of land use schemes is to plan land use, timely identify changes in land conditions, assess these changes, predict the consequences of negative processes and mitigation. 
It is important to develop modern technologies, a systematic approach, as well as a set of measures for the protection and rational use of the land it is necessary to conduct regular state land monitoring and use, and regularly identify and product development of negative processes.
The total land area in the administrative boundaries of the Tashkent region which is the object of study is 1525,4 thousand hectares for the date of January 1.2019 [8]. In the diagram below, we can see the changes observed in the land fund categories in 2010 and 2019 more clearly.

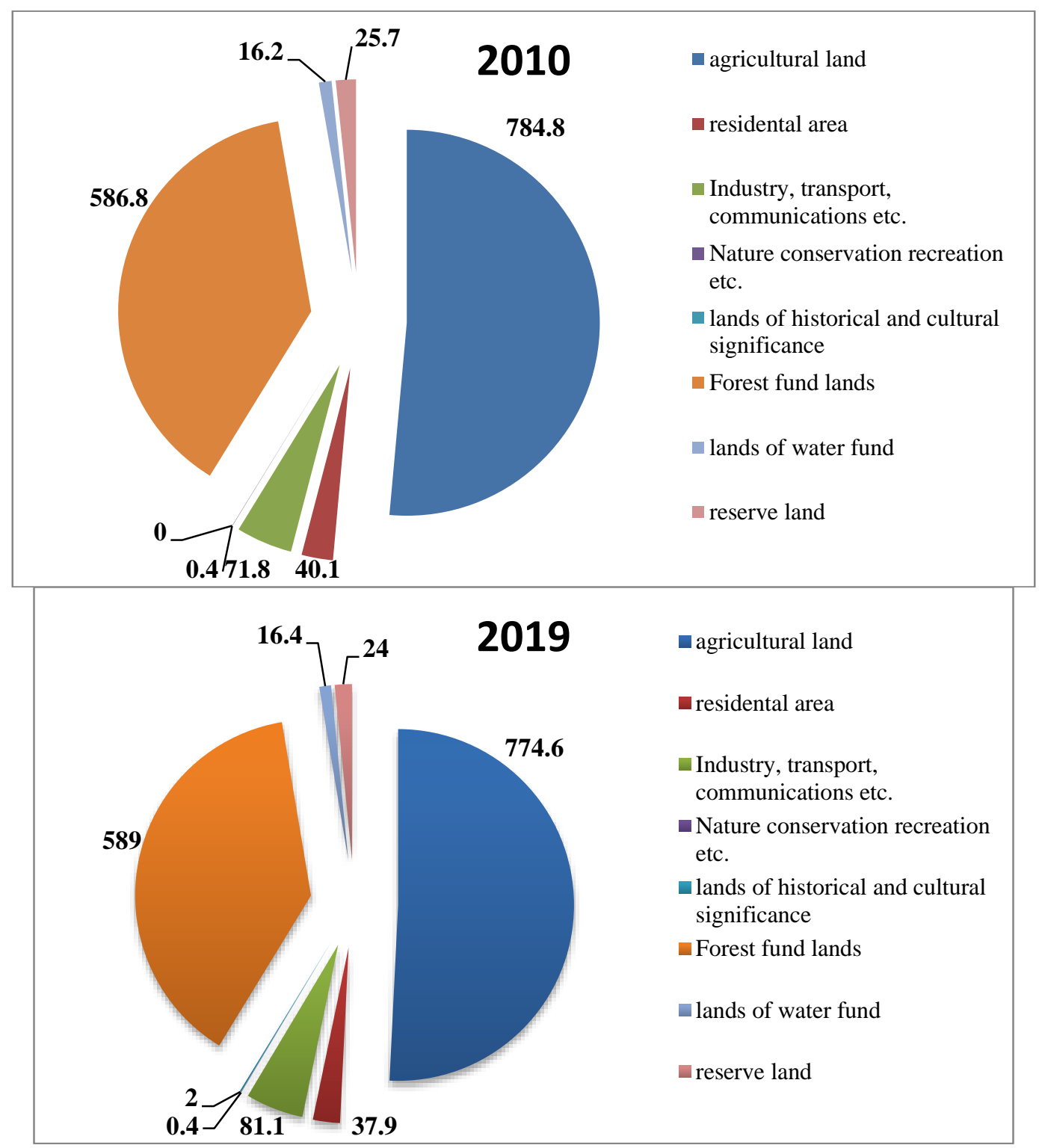

Diagram1. Land fund division of Tashkent province according to classification for years of 2010 and 2019. 
From the figure given in Diagram 1, we can see that agricultural land has decreased up to 10000 hectares in Tashkent region over the past 10 years. We can also see that the land occupied by industry, transport, communications, defence and other lands in the has increased up to about 10000 hectares by contrast. Changes were also observed in other lands in the regional land fund. The main reason for the loss and inefficient use of agricultural land is the lack of serious analysis of land monitoring based on remote sensing materials, which led to the lack of forecasting of land use. The shrinking of irrigated land is a clear indication of the inefficient use of land. In diagram 2 below, we can see the observed changes in the area of irrigated land from the years of 2000 to 2019 [8].

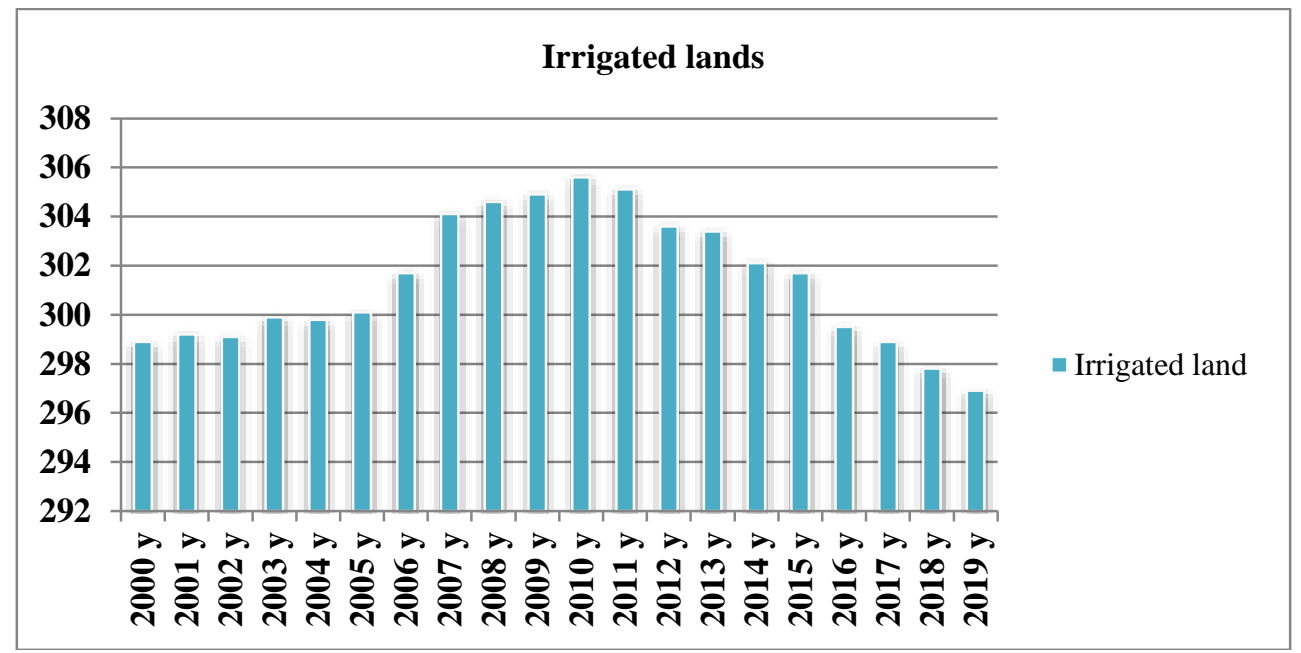

\section{Diagram 2. Quantitative changes of irrigated lands in Tashkent province from the year of 2000 to 2019.}

Diagram 2 shows that the quantitative changes over the last 20 years in irrigated lands of Tashkent region have been reflected. According to this diagram, 298,9 thousand hectares of fertile irrigated land was used in the region in 2000, but by 2010 the figure had risen slowly to 305,6 thousand hectares. However, since 2011 this figure had been declining slowly, and in 2019 the figure was 296,9 thousand hectares. Changes in the amount of irrigated land are primarily due to inefficient use of it, loss of use turn over and deterioration of quality. On the other hand, there have been cases of arbitrary seizure of land resources and the construction of housing because of human activities. As for the genesis of the problem, no analytical analyzes based on remote sensing data were conducted in the district land use departments. The condition of exiting lands has not been systematically analyzed using the methods mentioned above. Periodic changes in the district land fund were not strictly controlled based on spatial analysis.

Land use schemes have not been developed and the implementation of legal norms established for violations of the law by the population has not been ensured as a result, today there are disagreements between the state and the population over the use of land resources [9]. In particular, because of inspections conducted in Tashkent region in 2020 , violations were detected in 5 districts. According to the fact 690 hectares of land was illegally occupied and illegal housing was built 
in 3720 cases. We can see that about $79 \%$ of 690 hectares are fertile irrigated land or 546 hectares are fertile irrigated land. The majority of violations on irrigated lands are Zangiota district (94\%) and Tashkent district (96,7\%). We can also see that such cases have been observed in the territory of chards, vineyards and mulberry groves, as well as in other types of land (pastures, gray lands).

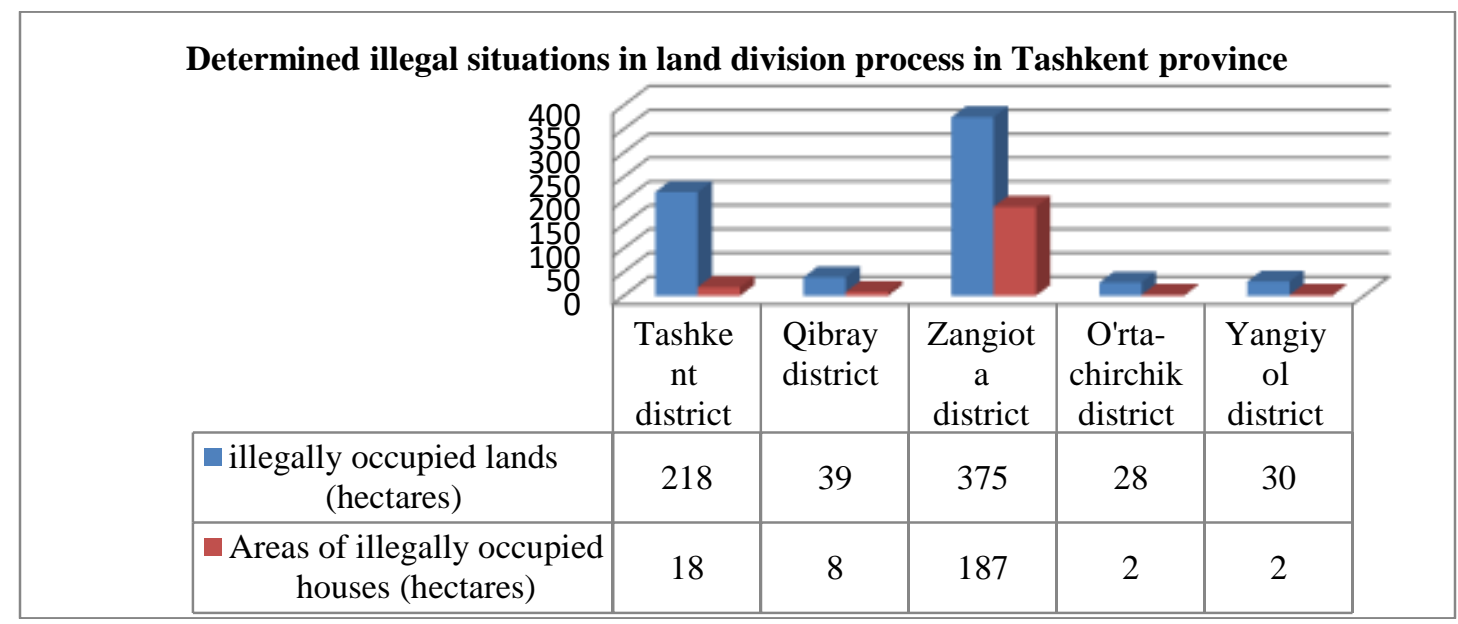

Diagram3.Determined illegal situations in land division process in Tashkent province.

Figure 3 below shows the arbitrarily occupied land and illegal constructions in 5 districts were mentioned above while the above mentioned negative processes are studied carefully and violations are recorded, it is advisable to create analytical forecast maps based on a statistical analysis of land fund categories, periodic remote sensing, satellite data, spatial analysis.

\section{METHODS}

The cartographic method of studying land conditions and its use is based on the creation of thematic maps, which integrate the natural environment - economic factors of the natural environment, as well as the condition of its landscapes. This method is effective in analyzing the dynamics of the land situation, assessing the location, solving problems of land management, assessing nature and changes in geographical relations in relation to natural and socio-economic processes.

The mathematical cartographic method is one of the main tasks in modelling dynamics of the development of negative processes and events to reflect observed changes in the category of the studied area, land fund. In this regard, it is necessary to analyze the land condition and its use, to develop forecasts for the development of adverse events. It is also advisable to develop recommendations to address identified negative processes.

RESULTS. Land use scheme was elaborated in the following scheme 1. 


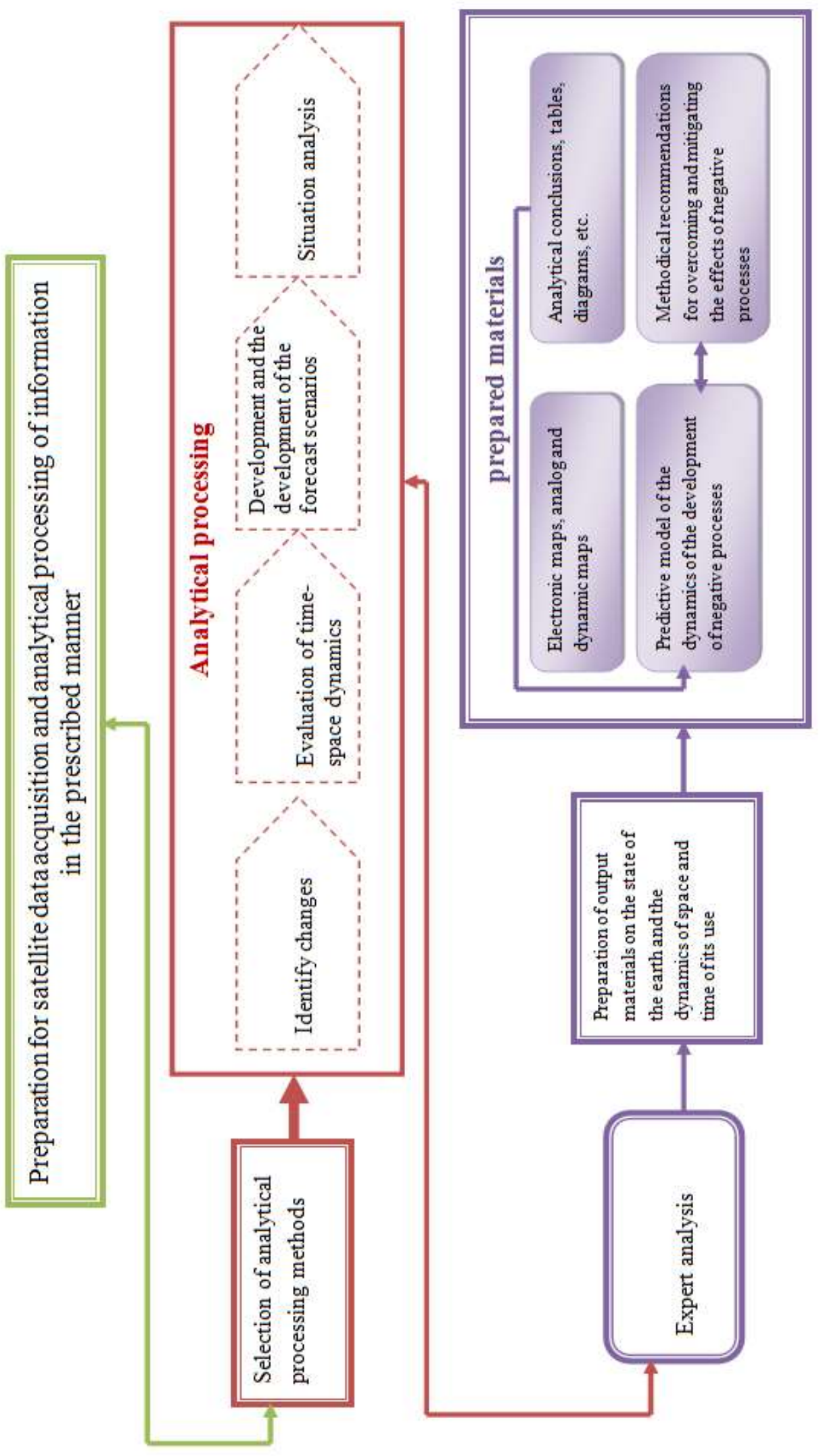




\section{DISCUSSION}

Many scholars have suggested a number of ideas for developing land use forecasts, for example:

Exiting land use in Uzbekistan is inefficient due to a number unresolved issues in land use: certain unsystematic management of land use, lack of forecasting and planning of rational land use and optimization of land use structure, active implementation of market principles in land use. Lack of attention to the restoration of land resources, lack of practice in assessing effectiveness of land use, etc[5].

The following features are of priority importance for the rational use of land fund of the Republic:

Long - term forecasts of land use;

For example, comprehensive scientific and technical programs for the period up 2000 and 2010.

Scheme of development and deployment of productive forces in the country. The content of projections on the use of land resources depends on their purpose, the size of the coverage area, forecasting tasks [8].

Despite the fact that leading scientists in the this field have provided scientific conclusions on the development of forecasts and schemes of land use, so far this problem has not found its scientific and practical solution. Forecasting schemes has not been developed. Methods of forecasting them have not been studied schemes for studying the condition of the earth and forecasting it for future using modern geo-media have not been developed. Scheme 1 which presented in the result section of the article outlines processes for creating forecast maps.

\section{CONCLUSION}

From the above mentioned it can be concluded that the following cartographic bases can be proposed based on the analysis of land condition and land use preparation of forecasts for development of adverse events and recommendations for their elimination:

Carrying out research on creation of land use schemes for efficient land use;

Analysis of land use and land resources;

Preparation of a cartographic basis for economic and mathematical problems on optimization of various solution of land management project;

Creating dynamic maps, forecast maps;

Creating maps that simultaneously reflect the forecast and dynamics of study area.

In determining the sphere of dynamic map use the following is taken into account: the chance of giving quantitative description of events and processes proportional to natural, socioeconomic and environmental characteristics of developing area and possibility of making recommendations on the most rational use of natural resources, environmental protection, etc will be created.

\section{REFERENCES}

1. Land Code of the Republic of Uzbekistan Tashkent 1998 y.

2. S.A.Tkachuk Land administration (Questions of general theory) $1986 \mathrm{y}$.

3. S.Avezboev., SNVolkov., "Land management design" 2004

4. E.RGolubkov Management decision making technology M., Kolos 2005

5. A.S., Chertovitsky, A.K., Bazarov Land use management Tashkent TIMI, 2009

6. A.R. Babajanov, A.M. Mukumov, S.R., Sharipov Territorial development. T., TIIAME. 2018

7. A.S., Altiev Land use economy Tashkent., 2019 
8. Materials of separate reports of the State Committee of the Republic of Uzbekistan on Land Resources, Geodesy, Cartography and State Cadastre for 2000-2019

9. Sultanovich, A. A., \& Ugli, M. M. D. (2019). Methods of forecasting and

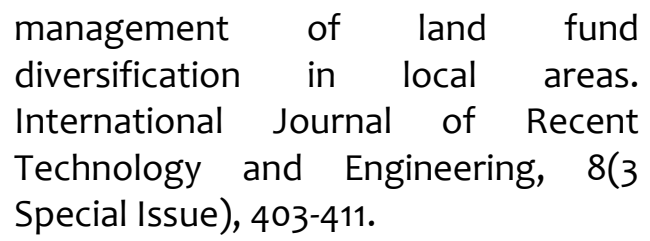

management of land fund International Journal of Recent Special Issue), 403-411. 